the secondary cathode where electron bombardment had occurred. The nature of this black deposit was not determined; but it might be noted that the same deposit was also found on the anode and glass bulb of the ionization gauge. Furthermore, the use of a water-cooled baffle in this system produced no change in the phenomena.

Thermionic emitters such as tungsten and alkaline earths are not seriously affected by the silicone, the emission being as good as in an ordinary demountable system. For example, over long periods, the tungsten filament of the ionization gauge could be operated as a thoriated emitter.

It is supposed that a silicone film on the bombarded electrode is decomposed, whereas a thermionic cathode remains hot enough to prevent much silicone remaining on it. It would seem, therefore, that great care should be exercised in interpreting the results of experiments which are made in vacua containing silicone vapour.

We wish to acknowledge the continued interest and help of Drs. H. Moss and C. S. Bull in the above work, and to thank Electronic Tubes, Ltd., for permission to publish these results.

A. Lempioki

A. B. McFarlane

Electronic Tubes, Ltd.,

Loudwater, High Wycombe, Bucks. Jan. 11

" "Advances in Electronice", 2, Garlick, G. F. J., "Cathodoluminescence", 158.

Bull, C. S., and Atherton, A. H., J. Inst. Elect. Eng., 97, III, 65 (1950).

\section{Determination of Phase Boundaries in Solid Alloy Systems by a Diffusion Technique}

THe accurate determination of equilibrium conditions in solid alloys containing three or more elements sometimes presents considerable difficulty when the alloying metals are present in only small proportions. Direct X-ray examination is not always feasible, and indirect methods, such as the measurement of electrical conductivity, may fail because the changes in properties are often comparatively slight.

We have recently been investigating the equilibrium constitution of aluminium-silicon-iron alloys containing 0.5 per cent iron and $0-0.75$ per cent silicon, that is, within the range of commercial-purity aluminium, at temperatures from $450^{\circ}$ to $600^{\circ} \mathrm{C}$. The technique used is both direct and simple, and since, so far as we can ascertain, it has not previously been applied in this way, a brief description may be of interest.

The principle of the method is to segregate the co-operating phases of an alloy on a scale which, although it allows equilibrium to be attained by a diffusion anneal, is yet sufficiently coarse to allow differential chemical analysis to be carried out without difficulty. This can be done very simply by hotrolling together, and so welding, fairly thick plates of different alloys to form a 'sandwich', the alloys being chosen so that certain phases will appear only in one layer of the composite sheet. The total analysis of the sandwich corresponds, of course, to the composition of alloy it is desired to investigate. The composite sheet is rolled down to an appropriate thickness, annealed until diffusion is complete, and the separate layers then analysed to determine the final distribution of the mobile element or elements.

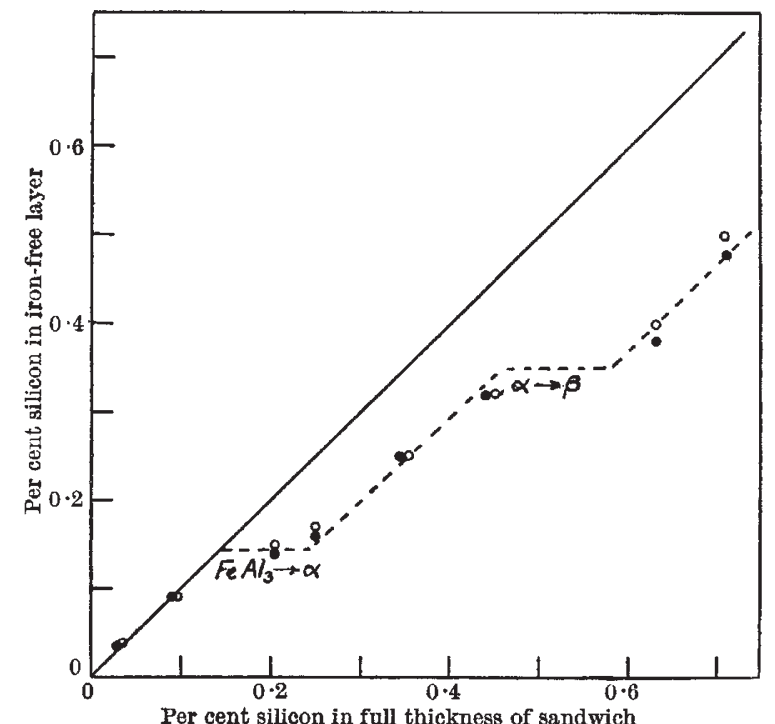

Results on alloys containing 0.5 per cent of iron heat-treated at $475^{\circ}$ C.: - , for $320 \mathrm{hr}$.; $\mathrm{O}-\mathrm{O}-$, for $500 \mathrm{hr}$.

In the aluminium-silicon-iron system, the solubility of iron is very small, and $\mathrm{FeAl}_{3}$ appears at quite low concentrations. All that is needed in this case is to determine the distribution of silicon between the aluminium solid solution and the $\mathrm{FeAl}_{3}$ phase, with which it is known to form, under appropriate conditions, two ternary compounds $\alpha\left(\mathrm{F}_{\theta}-\mathrm{Si}\right)$ and $\beta(\mathrm{Fe}-\mathrm{Si})^{1}$, and may also show solid solution effects. The sandwiches prepared, therefore, consisted of only two layers, of equal thickness, one containing 1.0 per cent iron and the other twice the concentration of silicon required in the final alloy.

At $550^{\circ}$ and $600^{\circ} \mathrm{C}$, material $1.0 \mathrm{~mm}$. thick was used. Samples for chemical analysis could then be taken from both sides of the heat-treated sheet by skimming in a lathe. At lower temperatures, the thickness was reduced to $0.25 \mathrm{~mm}$. to allow equilibrium to be attained in a reasonable time, and the procedure then adopted was to fix the sheet to a metal block with adhesive, with the iron-rich side uppermost, and to grind it down to a thickness of about $0.1 \mathrm{~mm}$. A determination of silicon on the $\mathrm{F} \theta \mathrm{Al}_{3}$-free side remaining and on the full thickness of the sandwich gave all the required information.

The accompanying graph shows the results obtained in some tests at $475^{\circ} \mathrm{C}$. In this we have plotted the percentage of silicon found in the $\mathrm{FeAl}$-free side against the total silicon determined on the full thickness of the sheet. The silicon combined with the $\mathrm{FeAl}_{3}$ is then given by the horizontal displacement of the experimental points from the line which has been drawn in at $45^{\circ}$. It will be seen that the approximate range of silicon contents over which $\alpha(\mathrm{Fe}-\mathrm{Si})$ and $\beta(\mathrm{Fe}-\mathrm{Si})$ are stable at this temperature can be determined without difficulty from the data.

It is hoped that it will be possible to publish elsewhere a detailed account of the results obtained by the application of this technique.

Research Laboratories,

C. E. Ransley

British Aluminium Co., Ltd., Chalfont Park,

Gerrards Cross,

Bucks. Jan. 5.

${ }^{1}$ Phillips, H. W. L., and Varley, P. C., J. Inst. Metals, 69, 317 (1943). 